\title{
A sobrevivência das pequenas empresas no desenvolvimento capitalista
}

\author{
OSWALDO GUERRA* \\ FRANCISCO TEIXEIRA**
}

The survival of small companies in the capitalist development. The role of small companies in capitalist development has raised, throughout the years, the analytical curiosity of economists and other social scientists. In spite of the enormous disadvantages that they possess in competing with big capital, there are innumerable reasons for their survival. The empirical evidence is clear in attesting the importance of small companies in terms of GDP share and job creation and, at the same time, their difficulties for surviving. This paper presents a theoretical revision, departing from Marx, Marshall, Steindl and Schumpeter up to some contemporary authors, concerning the role of the small companies in capitalist development, emphasizing the reasons and the difficulties for its survival.

Keywords: small companies; capitalism; competitiveness.

JEL Classification: O10.

\section{INTRODUÇÃO}

O papel das pequenas empresas no desenvolvimento capitalista tem despertado, ao longo dos anos, a curiosidade analítica dos economistas e outros cientistas sociais. Mais recentemente, a constatação empírica do significado econômico, social e político das pequenas empresas, em termos de contribuição para o PIB, geração de emprego, participação em diversos tipos de arranjos produtivos, entre outros aspectos, aguçou ainda mais essa curiosidade, ampliando a literatura sobre o tema.

\footnotetext{
"Doutor em Economia pela Unicamp. Professor Associado da Faculdade de Ciências Econômicas da Universidade Federal da Bahia. oguerra@ufba.br.

**Doutor pela Universidade de Sussex, Inglaterra. Professor Titular da Escola de Administração da Universidade Federal da Bahia. E-mail: teixeira@ufba.br.

Os autores agradecem aos comentários e sugestões de dois pareceristas anônimos. Submetido: Novembro 2007: Aprovado: Agosto 2008.
} 
No caso brasileiro, as micro e pequenas empresas detinham, em 2002, 20\% de participação no PIB e geravam $60 \%$ dos empregos formais no setor privado. Em conjunto, elas responderam, naquele mesmo ano por $99,2 \%$ do número total de empresas formais, $57,2 \%$ dos empregos totais e $26 \%$ da massa salarial. Essa participação é ampliada quando se incorpora a economia informal, composta basicamente pelo pequeno capital. Em 2003, existiam cerca de 10,3 milhões de empreendimentos informais que ocupavam 13,8 milhões de pessoas (Sebrae, 2005).

Apesar do peso econômico dessas empresas, seu ciclo de vida costuma ser curto. Em 2002, 49,4\% delas encerraram suas atividades com até 2 anos de existência, $56,4 \%$ com até 3 anos e $59,9 \%$ com até 4 anos, sendo que $75 \%$ das que deixaram de existir ocupavam entre 2 e 9 pessoas (Sebrae, 2005). A chamada taxa de mortalidade, em 2005, foi de 22\% (Vox Populi, 2007). Portanto, ao mesmo tempo em que a pequena empresa cumpre um importante papel econômico e social, ela enfrenta dificuldades para sobreviver.

O principal objetivo deste artigo é fazer uma revisão teórica acerca do papel das pequenas empresas no desenvolvimento capitalista, destacando as razões e as dificuldades para sua sobrevivência. Para tal, além desta introdução, ele contém três seções. Nas duas primeiras, as visões de Marx, Marshall, Steindl e Schumpeter e de alguns autores contemporâneos sobre o tema são revistas. Nas considerações finais, sintetiza-se, a partir da revisão empreendida, as principais razões e dificuldades para a sobrevivência deste tipo de unidade produtiva.

\section{PEQUENA EMPRESA NO AVANÇO DO CAPITALISMO}

Marx

A sobrevivência e expansão da pequena empresa em uma economia capitalista são tratadas por Marx (1867) no âmbito do processo de acumulação de capital. Como se sabe, a exemplo dos economistas clássicos (Adam Smith e David Ricardo), Marx é adepto da teoria do valor trabalho que, simplificadamente, afirma que o valor de uma mercadoria depende da quantidade de trabalho nela incorporada.

Existe, todavia, uma significativa diferença entre Marx e os clássicos. Estes acreditavam na existência de leis naturais em cada época histórica (escravismo, feudalismo, capitalismo) e por isso trabalharam com categorias gerais, como o valor, utilizadas em qualquer sistema de produção. Em Marx, o valor não existe em qualquer sociedade porque o produto do trabalho humano não possui a forma de mercadoria em todas as épocas históricas. A forma valor é própria do sistema capitalista porque, apenas nele, o trabalho assume a forma de uma mercadoria como outra qualquer. Para que isso fosse possível, o trabalhador precisou ganhar sua dupla liberdade: não ser propriedade de nenhum senhor; e ser despossuído de qualquer meio de produção. Com esse entendimento, Marx buscou construir o conceito de capital a partir do valor para, então, explicar a dinâmica capitalista. 
Assim ele discute, em sequência, a mercadoria, o valor, o dinheiro, o capital e seus movimentos (Belluzzo, 1987; Napoleoni, 1988).

Ao percorrer esse circuito, Marx mapeia três etapas do processo histórico de transição e constituição da produção capitalista: a cooperação simples, a manufatura e a grande indústria. A cooperação simples é caracterizada, basicamente, por produtores independentes, proprietários de seus meios de produção, insignificante divisão do trabalho e reduzido emprego de maquinaria. Dessa etapa pré-capitalista, chega-se à manufatura, na qual já se identifica a divisão do trabalho e a figura do capitalista. Entretanto, o capital ainda não subordina totalmente o processo de produção por restarem, entre outras coisas, tênues resquícios de trabalho artesanal. Mas, ao aparecer o capitalista surge o capital, um valor que se expande pela sua transformação em mais valor. Essa busca incessante de valorização é o móvel do capitalismo, funciona como se fosse uma lei coercitiva e quem a impulsiona é a concorrência. Esta faz com que o progresso técnico eleve os gastos em bens de produção (capital constante) comparativamente às despesas com força de trabalho (capital variável), aumentando o tamanho da unidade produtiva e desintegrando as formações pré-capitalistas (Mazzucchelli, 1985; Belluzzo, 1987).

O emprego crescente de inovações tecnológicas implica, portanto, o desenvolvimento de unidades mecanizadas para a grande indústria, enquanto as demais, usuárias em menor intensidade de capital constante, ocupariam a categoria de pequenas empresas. A cada inovação incorporada pelas grandes empresas, provocando uma racionalização cada vez maior do processo de trabalho, as pequenas empresas sofreriam impactos negativos advindos da manutenção de processos tornados obsoletos.

Nesse quadro dinâmico montado por Marx, pode-se perceber a mutação sofrida pelas pequenas empresas. Os adjetivos pequeno ou grande, usados para denominar as unidades produtivas, servem para diferenciar as diversas formas em transição e não apenas a dimensão quantitativa de tamanho. Vale dizer, quando surge a manufatura como a primeira forma de produção sustentada na divisão do trabalho, ela assume o qualitativo de "grande empresa" em relação à forma pretérita de produção doméstico-artesanal, típica da cooperação simples, considerada "pequena empresa" (Sato, 1977, p. 76).

Na medida em que a transição da cooperação simples à grande indústria avança e se aprofunda, os trabalhadores se convertem em proletários inteiramente subjugados pelo capital e pelos capitalistas. Os próprios detentores de capital são expropriados por outros capitalistas, através do processo de concorrência, concentração e centralização de capitais.

A batalha da concorrência é conduzida por meio da redução do preço das mercadorias. Não se alterando as demais circunstâncias, o barateamento das mercadorias depende da produtividade do trabalho e este da escala de produção. Os capitais grandes esmagam os pequenos. Demais, lembramos que, com o desenvolvimento do modo de produção capitalista, aumenta a dimensão mínima do capital individual exigido pa- 
ra levar adiante um negócio em condições normais. Os capitais pequenos lançam-se, assim, nos ramos de produção de que a grande indústria se apossou de maneira esporádica ou incompleta. A concorrência acirra-se então na razão direta do número e na inversa da magnitude dos capitais que se rivalizam. E acaba sempre com a derrota de muitos capitalistas pequenos, cujos capitais ou soçobram ou se transferem para as mãos do vencedor. Além disso, a produção capitalista faz surgir uma fôrça inteiramente nova, o crédito. Este, de inicio, insinua-se furtivamente, como auxiliar modesto da acumulação e, por meio de fios invisíveis, leva para as mãos dos capitalistas, isolados ou associados, os meios financeiros dispersos, em proporções maiores ou menores, pela sociedade, para logo se tornar uma arma nova e terrível na luta da concorrência e transformar-se, por fim, num imenso mecanismo social de centralização de capitais (Marx, 1867, livro 1, v. 2, p. 727).

Nessas condições, tudo levava a crer que as pequenas empresas estariam fadadas a sucumbir perante as grandes, pois o acesso a novas tecnologias e ao crédito, bases para a sobrevivência e expansão das empresas no modo de produção capitalista, é muito mais fácil para a grande empresa, o que realimenta o processo de centralização do capital (eliminação do pequeno pelo grande capital). A análise de Marx, todavia, não legitima a tese da destruição inexorável da pequena empresa. Como já destacado, na sua reconstituição do processo histórico de surgimento da produção capitalista, o desaparecimento de pequenas unidades produtivas referia-se à morte de formas pré-capitalistas. Constituída a produção capitalista, essa eliminação é de outra ordem: vincula-se a reacomodação do pequeno capital sob a dominação de blocos mais poderosos de capital. "Os termos relativos pequena e grande não mais dizem respeito a unidades produtivas de estrutura essencialmente distinta, mas às descontinuidades das escalas de tamanho e poder de mercado diferenciado de capitais" (Sato, 1977, p. 91).

A destruição da pequena empresa não acontece devido ao movimento contrário à centralização do capital: sua dispersão. Essa dispersão do capital fomenta o nascimento contínuo de novas empresas e a sobrevivência de outras que, sendo complementares às grandes, podem conviver com estas lado a lado. Embora legalmente independentes, as pequenas empresas precisariam, todavia, satisfazer as condições técnicas e administrativas ditadas pela grande empresa. Assim procedendo, elas conservam a relação que lhes garante a sobrevivência.

As pequenas empresas com menor capacidade de incorporar progresso tecnológico passariam a depender da grande empresa, em uma relação subordinada devido a seu maior custo de produção. Desse modo, para se manterem competitivas, teriam que pagar salários menores e estes, juntamente com os custos de produção mais elevados, tornar-se-iam parâmetros para a grande unidade.

Dessa análise de Marx brota um aspecto funcional da existência da pequena empresa: a acumulação de capital das pequenas unidades que não incorporam novas tecnologias no seu processo produtivo seria viabilizada pela intensificação 
do capital nas grandes firmas, o que criaria um exército de reserva de operários e resultaria em menores salários. O aumento da composição orgânica - relação entre capital constante e capital variável, ou ainda, entre bens de capital e força de trabalho - dos setores produtivos intensivos em capital não impediria e até colaboraria para que as pequenas empresas realizassem sua acumulação sob condições aparentemente adversas, dando, dessa maneira, condições para sua sobrevivência e, até mesmo, expansão. Assim, o grande capital e o pequeno cumpririam funções complementares no processo de acumulação capitalista.

\section{Marshall}

A visão de Alfred Marshall sobre o papel das pequenas empresas na dinâmica do sistema econômico capitalista é bem distinta da de Marx. Esta visão, bem como sua famosa analogia das firmas de uma indústria com as árvores de uma floresta, em sua principal obra, Princípios de Economia (1890), apoia-se em três premissas básicas:

- a lei de sobrevivência do mais apto;

- a ideia de que a evolução de qualquer organismo se processa dentro de uma estrutura constituída por funções ao mesmo tempo diferenciadas (individualizadas) e integradas (conexas); e

- o conceito de ciclo vital (nascimento-auge-declínio) que marca a evolução dos organismos, sejam físicos ou sociais (Sato, 1977).

No mercado (floresta), as firmas, confrontadas com a necessidade de expandir o volume de produção, se envolveriam em uma busca incessante por eficiência produtiva. Nessa busca, as empresas que assumissem uma posição de vanguarda, adotando uma adequada divisão interna do trabalho, teriam maiores chances de se expandir e sobreviver.

Isto porque essa divisão do trabalho, conceito que Marshall capta em Adam Smith, ensejaria a especialização das funções técnicas e administrativas, podendo resultar em uma redução do custo unitário mesmo diante de um aumento na escala de produção (economias de escala internas às firmas). Poderiam ocorrer também sinergias entre unidades produtivas dentro de uma mesma indústria, desde que elas possuíssem vínculos umas com as outras. Em um cenário no qual a diferenciação de atividades entre essas unidades produtivas e a integração entre elas se fizessem mais presentes, ocorreriam benefícios recíprocos, gerando ganhos competitivos, ou seja, economias de escala externas à firma (Marshall, 1890, p. 229).

No caso de economias de escala externas à firma, elas seriam acessíveis tanto às pequenas quanto às grandes empresas, pois dependeriam do tamanho da indústria e não, necessariamente, do tamanho de uma firma individual. Já as economias de escala internas à firma gerariam vantagens de custos associadas ao tamanho das unidades produtivas.

Nesse cenário, no qual se destacam a divisão do trabalho e as economias de escala, especialmente as internas às firmas, ficam claras as condições adversas com 
as quais as pequenas empresas conviveriam. A divisão de tarefas na grande empresa criaria a oportunidade para a especialização do trabalho e a utilização de mão de obra e equipamentos específicos para as diversas etapas do processo produtivo, estimulando a instalação de um maquinário cada vez mais caro e gerador de maior produtividade. Já nas pequenas empresas, o maquinário seria de uso genérico, pois a baixa capitalização, além da pequena escala, não lhes permitiria comprar equipamentos especializados. Na grande empresa, a especialização é a palavra de ordem, presente, por exemplo, na área técnico-administrativa, expressão da separação entre propriedade e gestão. $\mathrm{Na}$ pequena empresa tem-se a figura do empresário "faz de tudo" que, ao lidar com todos os problemas do dia a dia, ficaria incapacitado de pensar a empresa do ponto de vista estratégico. A esse conjunto de vantagens das grandes empresas incorporam-se aquelas conquistadas pela sua atuação no mercado, tais como: compras de grandes lotes; redução nas tarifas de transportes; e ganhos adquiridos pelos gastos em propaganda (Sato, 1977).

Dado essas condições adversas, o que impediria a concentração da produção com o surgimento de uma situação de monopólio e a eliminação das pequenas empresas? Como recorda Steindl (1945, p. 12), Marshall oferece duas respostas:

- "o crescimento da empresa não pode continuar indefinidamente porque as aptidões e a energia dos empresários (ou de seus herdeiros) estão sujeitas a involuir depois de certo tempo;

- em muitos ramos, as economias de escala são neutralizadas pela dificuldade de ampliar o mercado da empresa".

Nessa segunda resposta, Marshall pressupõe que a empresa só pode expandir suas vendas mediante uma redução de preços, prática possível em mercados considerados imperfeitos. Isso surpreende Steindl, pois Marshall prioriza em sua análise mercados nos quais impera a concorrência perfeita. Nesse tipo de estrutura de mercado, a empresa submete-se à ditadura da competição, sendo uma mera tomadora de preços.

Na primeira resposta, à qual Marshall dá maior ênfase, a noção de concorrência perfeita é marcante e a premissa do ciclo vital da empresa está claramente subjacente. Para Marshall, os ramos industriais, mesmo sofrendo com a involução das habilidades empresariais, poderiam se expandir ao longo do tempo devido à substituição contínua de empresários decadentes por novos empresários que surgem e crescem. Desse modo, uma oferta elástica de empresários e a inexistência de barreiras à entrada impediriam que algum empresário particular se aproveitasse das economias de escala de forma duradoura para, em proveito próprio, formar um mercado concentrado.

Como sempre haveria empresas crescendo, decaindo e morrendo (ciclo vital), pode-se eleger uma "empresa representativa" da indústria que não é jovem e crescente, nem decadente, nem de tamanho inusitadamente grande ou dotada de vantagens incomuns (Steindl, 1945). Seria uma unidade produtiva que, no equilíbrio de longo prazo, ficaria congelada em um dado tamanho ótimo, auferindo apenas 
lucros normais. Crescer além deste tamanho implicaria custos unitários crescentes (deseconomias de escala).

Em suma, apesar das condições adversas enfrentadas pelas pequenas empresas, a tendência, no longo prazo, a seu inexorável fim seria contrarrestada pela contínua substituição de empresários e unidades ineficientes por outros dinâmicos e eficazes, como as árvores de uma floresta que se adaptam às transformações no meio ambiente. No capítulo XII do livro IV dos Princípios de Economia (1890), Marshall faz referência à disposição de certas pessoas para reunir capital e mão de obra e assumir riscos na instalação de uma pequena atividade econômica, pela satisfação de serem chamados de "homens de negócios", espécie de intermediários entre o operário e o capitalista. Além disso, o sistema de subcontratação de pequenas oficinas ou trabalho caseiro, utilizado pelo capitalista contratante para evitar registros de grande número de trabalhadores em seus livros contábeis, também explicaria a não expulsão completa do pequeno pelo grande capital.

\section{Steindl}

Steindl, no primeiro capítulo do seu livro Pequeno e grande capital (1945), no qual discute os problemas econômicos associados ao tamanho das empresas, faz duas grandes objeções à análise de Marshall: a superestimação da importância da aptidão pessoal do empresário; e a rapidez com que apareceriam no cenário novos empresários dotados de capital.

Para Steindl, ao contrário do que propõe Marshall, a oferta de empresários é bastante inelástica. Ele também discorda da tese marshalliana de que, acima do tamanho ótimo, os custos de ampliação das vendas seriam superiores aos ganhos advindos das economias de escala, pois ela pressupõe um "estado estacionário" no qual não ocorre crescimento da demanda agregada e setorial. Quando há crescimento do mercado, independentemente do esforço das firmas existentes, estas terão acesso a demandas adicionais sem que isso implique custos complementares de vendas. Com a ampliação do mercado, a escala da firma representativa se elevaria de tal modo que as firmas maiores gozariam, cada vez mais, de vantagens diferenciais (Sato, 1977).

Steindl procura demonstrar a impossibilidade de crescimento das pequenas unidades e a inexorabilidade da tendência à monopolização, apresentando várias evidências. Em primeiro lugar, as pequenas empresas, embora possam sobreviver graças à preservação de um mercado cativo, teriam de crescer muitas vezes para que pudessem atingir o tamanho de uma grande empresa. Um crescimento desse tipo tomaria tanto tempo que tornaria a teoria irrelevante para qualquer aplicação prática. Além disso, seria extremamente improvável, tendo em vista a altíssima taxa de mortalidade das pequenas empresas, que qualquer pequeno empresário conseguisse de fato completar sua ascensão até o tamanho de uma grande empresa. Ou seja, o ciclo vital não teria fundamento. "Na verdade ocorre um crescimento, mas ele é lento; e, na maioria das vezes, a árvore nunca cresce, por essa razão, a 
decadência e morte das grandes empresas só podem ser lentas; caso contrário nada haveria que as substituísse" (Steindl, 1945, p. 18).

Em segundo lugar, por sofrer restrições de crédito, a capacidade de endividamento das firmas pequenas é limitada, o que dificulta a sua passagem à categoria de grande. Se as grandes empresas dispõem de rentabilidade mais elevada e maior liquidez, elas fortalecem ainda mais sua capacidade de acumulação por meio de fontes externas (Steindl, 1945).

Em terceiro lugar, mesmo que se aceite a ideia de Marshall de que algumas firmas grandes não deixam de ser firmas menores crescidas, a alta taxa de mortalidade das pequenas empresas corrobora uma ideia contrária: a diminuta probabilidade do surgimento de grandes empresas a partir das pequenas. Em outras palavras, a elasticidade de oferta de grandes empresários é muito baixa, especialmente no curto prazo. Quase sempre, uma grande empresa não surge pela via do crescimento das pequenas, mas sim mediante a formação de novas sociedades anônimas ou por meio de fusões. A constituição de sociedades anônimas pressupõe a centralização de capitais individuais, cuja disponibilidade não é inesgotável. Já as fusões pressupõem a existência prévia de firmas pequenas e médias que possam oferecer condições de lucratividade após a fusão, algo que também não se encontra de forma abundante (Steindl, 1945).

Portanto, a alta elasticidade de oferta de empresários só ocorreria no segmento de pequenas empresas onde, por sua vez, a intensa concorrência comprimiria a taxa de lucro e aumentaria a taxa de mortalidade de tal forma que se criaria um círculo fechado de vida e morte de pequenas empresas.

Aqui surge, novamente, a mesma questão já antes levantada: diante de tantas adversidades, como sobreviveria a pequena empresa? Steindl, apesar de acreditar na inevitável eliminação do pequeno capital, apresenta algumas respostas (Sato, 1977).

1. As pequenas empresas só desapareceriam na medida em que as grandes crescessem, tomando-lhes o mercado. Esse processo pode ser lento e estaria associado a transformações nos padrões competitivos que ocorrem com $\mathrm{o}$ avanço do capitalismo em direção à maturidade, no qual predominam os oligopólios concentrados, como ele procura demonstrar na sua principal obra - Maturidade e estagnação no capitalismo americano, de 1952.

2. A maioria das pequenas empresas seria encontrada em setores ou espaços geográficos onde os incentivos para inovações poupadoras de trabalho fossem escassos e a mão de obra barata e desorganizada; isso permitiria que a redução nos preços das mercadorias fosse facilmente transformada em salários mais baixos.

3. No oligopólio menos concentrado ou competitivo, anterior, portanto, à fase de maturidade do capitalismo, as empresas reconhecidas como líderes em custos não teriam interesse em eliminar as pequenas empresas que ocupassem fatias pouco significativas do mercado, pois o custo de eliminação não compensaria os ganhos em termos de expansão do poder de mercado. 
Em alguns casos, a manutenção das pequenas empresas poderia ser decorrente de razões políticas: não caracterizar explicitamente, ainda que ela exista, uma situação de monopólio. As grandes empresas prefeririam expandir-se para outras indústrias, ampliando a sua área de influência.

4. Em uma sociedade capitalista, a posição social do empresário é valorizada. Sendo assim, muitos querem montar seus próprios negócios e, uma vez estabelecidos, farão tudo para manter o status de empresário, ainda que pudessem ganhar mais na função de gerente assalariado. Além disso, ser empresário significaria, antes de tudo, dar emprego a si próprio e a seus familiares.

Ainda que essas quatro situações permitam a sobrevivência das pequenas empresas, essa sobrevivência seria, para Steindl, precária. Com o avanço do desenvolvimento capitalista, a eliminação do pequeno capital inevitavelmente ocorreria. Em um post scriptum, produzido vinte e cinco anos depois da primeira edição, em 1945, de Pequeno e grande capital, Steindl reconheceu que a evolução dos fatos econômicos não comprovou sua tese da eliminação inexorável do pequeno capital, mas não se dispôs a explicar os motivos para a divergência entre teoria e realidade. Como o desenvolvimento capitalista não foi interrompido, pode-se concluir que esse desenvolvimento não exigiu a eliminação das pequenas empresas, como supunha Steindl.

\section{Schumpeter}

A exemplo dos três pensadores já analisados, Schumpeter enxerga o capitalismo como um sistema em contínua transformação. Essa transformação assume, contudo, um significado distinto, uma vez que a inovação, técnica ou organizacional, é colocada no centro de sua análise e a ela Schumpeter dedica especial atenção.

Para o autor, a inovação é responsável pelo desencadeamento de um processo de "destruição criadora" que revoluciona continuamente as antigas formas de produção, criando elementos novos. Isto porque, "o impulso fundamental que põe e mantém em funcionamento a máquina capitalista procede dos novos bens de consumo, dos novos métodos de produção ou transporte, dos novos mercados e das novas formas de organização industrial criados pela empresa capitalista" (Schumpeter, 1942, pp. 105 e 106).

O lucro é o motivador do esforço inovativo. Quanto mais o empresário vislumbre a possibilidade de manter o monopólio da inovação, mais estimulado ele estará para se envolver nesse esforço. Quanto mais êxito tiver o empresário em preservar para si os ganhos oriundos desse monopólio, maiores serão as assimetrias competitivas entre ele e seus concorrentes.

Schumpeter considera a grande empresa como o espaço produtivo mais propício para a gestação da destruição criadora, pois "num negócio em larga escala são possíveis um arranjo mais adequado e uma utilização de fatores de produção 
melhor do que em negócios menores; e, além disso, é possível a escolha de uma localização mais favorável" (Schumpeter, 1912, p. 90).

Ou seja, a magnitude dos lucros gerados, o acesso facilitado ao crédito, a substituição do empreendedor individual por uma equipe de especialistas e a institucionalização da busca por inovação nos departamentos de pesquisa e desenvolvimento, no interior da grande empresa em articulação com universidades, fazem desse tipo de unidade produtiva a locomotiva que move o capitalismo.

Em que pese essa visão, facilmente dedutível dos escritos de Schumpeter, ele não descarta a possibilidade da inovação ser realizada por pequenas empresas nem, tampouco, identifica qualquer tendência inexorável de eliminação do pequeno capital. Crescimento, estagnação e morte das firmas dependeriam do ritmo da introdução de inovações e da possibilidade dos novos métodos de produção ou de organização industrial conviverem com antigas formas.

Além disto, Schumpeter (1942), a exemplo de Steindl, encontra razões políticas para a sobrevivência do pequeno capital, ao considerar que a estrutura política de uma nação poderia ser seriamente afetada pela falência de um grande número de pequenas empresas, cujos donos, gerentes, dependentes, agregados e conexões contam, quantitativamente, nas urnas. Vale dizer: não houvesse viabilidade econômica para a pequena empresa, ela teria uma funcionalidade política que justificaria esforços em prol da sua sobrevivência.

\section{PEQUENA EMPRESA NO CAPITALISMO CONTEMPORÂNEO}

Após as importantes contribuições dos autores revisados na seção anterior, o papel da pequena empresa no desenvolvimento de sociedades capitalistas teve pouco espaço na literatura econômica. A hegemonia do pensamento neoclássico e a suposição de mercados perfeitamente concorrenciais, nos quais as firmas são homogêneas em termos de tamanho e comportamento competitivo, contribuíram para impedir um maior aprofundamento sobre as condições efetivas que estimulam ou desestimulam o surgimento e crescimento dos pequenos negócios.

Esse quadro começou a mudar a partir da década de 1970. A crise do padrão fordista de produção em massa e a emergência da terceira revolução industrial, capitaneada pela microeletrônica, estimularam a recuperação do interesse pelo tema. Um vasto número de estudiosos passou a trabalhar com a hipótese de que essa nova fase do desenvolvimento capitalista exigiria padrões organizacionais flexíveis, capazes de atender à demanda de mercados cada vez mais segmentados e exigentes e de enfrentar o acirramento da competição globalizada. A pequena empresa, pela suas características intrínsecas, estaria em uma posição privilegiada para atender aos novos requisitos competitivos, uma vez que, além da possibilidade de adotar padrões organizacionais e produtivos flexíveis, poderia se beneficiar da crescente redução dos preços dos equipamentos de base microeletrônica (Winter, 1995; Lemos, 2003).

Essa hipótese foi defendida, pioneiramente, no trabalho de Piore e Sabel (1984) 
e tem como primeiras evidências empíricas os casos bem-sucedidos de clusters em setores tradicionais, como têxteis e calçados, na chamada Terceira Itália, e de alta tecnologia, exemplificado pela microeletrônica no Vale do Silício nos EUA. Assim, um novo paradigma produtivo e organizacional (especialização flexível) estaria surgindo, em substituição ao fordismo, caracterizado pela especialização produtiva de pequenas empresas, muitas vezes aglomeradas territorialmente, que contariam com flexibilidade para atender aos requisitos dos mercados turbulentos e, cada vez mais, segmentados. Seguindo essa perspectiva, Scott e Storper (1987), quando analisaram a nova geografia da acumulação flexível, defenderam a proposta da emergência de um novo paradigma não apenas produtivo e organizacional, mas também de localização, no qual flexibilidade e localismo seriam as principais características.

De acordo com Winter (1995), parece não haver muitas dúvidas em torno da existência de uma tendência geral de expansão do papel da pequena empresa, assim como de pequenas unidades produtivas de grandes empresas, no capitalismo contemporâneo. De fato, as conclusões apresentadas por Loveman e Sengenberger (1991), baseadas em estudos empíricos conduzidos em nove países, indicam que, apesar dos problemas metodológicos envolvidos em tais mensurações, existe uma tendência do emprego se concentrar, cada vez mais, em unidades produtivas menores.

No entanto, essas evidências não são capazes de resolver a controvérsia em torno do papel dos pequenos negócios na expansão do emprego, da renda e do bem-estar social. Ao revisar os estudos disponíveis em relação ao emprego, Winter (1995) chega à conclusão de que a defesa do maior potencial de geração de postos de trabalho na pequena empresa não é sustentada por pesquisas empíricas cuidadosas. Os problemas enfrentados pelo que Winter chama de "now fading conventional wisdom” estão relacionados com a lógica estatística.

Em primeiro lugar, é necessário distinguir entre criação bruta e líquida de novos empregos. Isso porque, assim como criam uma quantidade desproporcional de postos de trabalho, os pequenos negócios também os destroem, devido às suas altas de taxas de mortalidade. Em segundo lugar, as estatísticas não captam a dinâmica da redução e do crescimento das firmas de um dado ano base, principalmente quando o tamanho da firma é definido em função do número de empregados. As conclusões de Winter, largamente suportadas pelo trabalho empírico de Davies, Haltiwanger e Schuh (1996), são duas: não é possível postular variações na taxa de criação de empregos por conta do tamanho da firma; e não há evidente razão para se pensar que a taxa de criação líquida de empregos seria muito diferente se um dado setor de atividade fosse organizado com 50 firmas de 20 empregos ou com uma única firma de mil empregados.

Essas conclusões remetem para as dificuldades na definição do conceito de pequenas empresas, conforme observado por Tagliassuchi (1987) e Julien (1993). Elas são, tradicionalmente, definidas pela sua dimensão, medida em termos do número de empregados e/ou do faturamento. No entanto, esse tipo de procedimento pode redundar em problemas tanto de ordem estatística, como de ordem teórica. Como sugere Montaño (1999), ao definir a pequena empresa como aquela que 
emprega um número reduzido de trabalhadores, estar-se-ia conferindo a uma realidade empírica o status de teoria. Assim, uma empresa altamente capitalizada e lucrativa, mas que emprega poucas pessoas, devido ao seu alto grau de automação e terceirização, seria classificada como pequena.

Para superar esses problemas, esse autor sugere que as pequenas empresas sejam caracterizadas a partir de suas respectivas composições orgânicas do capital. Assim procedendo, poder-se-ia constatar que elas, comparativamente com a média do ramo de atividade, seriam menos desenvolvidas em termos tecnológicos, apresentando uma baixa relação capital constante/capital variável, menos produtivas, pois teriam menores escala e maiores custos de produção, e menos lucrativas. Portanto, a inserção socioeconômica da pequena produção seria qualitativamente distinta da grande empresa, sendo que o pequeno empresário, em termos da sua inserção social, não poderia ser confundido com o grande capitalista. Esse tipo de abordagem indica que o pequeno negócio pode ser melhor compreendido com a ajuda de uma abordagem multidisciplinar que permita desvendar a sua gênese e inserção na sociedade capitalista.

Nesse sentido, a perspectiva funcionalista justifica políticas voltadas para a criação de pequenas empresas pelo fortalecimento dos valores burgueses, associados à propriedade privada, e pela garantia da estabilidade política (Winter, 1995). Porém, esse tipo de perspectiva não consegue responder à questão já posta na seção anterior: por que sempre existiriam pessoas dispostas a assumir riscos, reunindo mão de obra e capital na instalação de uma pequena empresa, pela satisfação de serem chamados de homens de negócios, ainda que pudessem ganhar mais na função de gerente assalariado?

Analisando o caso dos EUA, Wright Mills (1969) observa que na formação histórica daquele país, as antigas classes médias eram constituídas por pequenos proprietários de terras, desde o início produzindo excedentes para o mercado, e pequenos homens de negócios independentes. Esse mundo de pequenos empresários, segundo o autor, equilibrava-se por si mesmo, de forma automática, por meio das ações individuais, dispensando o poder de uma autoridade central. Relaciona-se, desse modo, essa formação histórica à ideologia do pequeno negócio - visto como um meio de fortalecer os valores burgueses - e à estabilidade política e, segundo o próprio Mills, à mágica noção de equilíbrio da Teoria Econômica.

Para Mills, essa situação foi se modificando ao longo da história, resultando que os pequenos empresários independentes se encontravam, no século XX, em posição completamente diferente.

Os empresários livres da antiga classe média representam pequena proporção da população ativa. Já não têm a mesma posição social de antes. Já não são modelo de aspiração para a maior parte do povo. Já não preenchem seu papel clássico de integração da estrutura social em que vivem e trabalham. São esses os índices do seu declínio. As causas compreendem todas as transformações da moderna sociedade industrial. 
As consequências repercutem profundamente na América do século XX. (Mills, 1969, p. 34)

As "transformações da moderna sociedade industrial" podem ser reconhecidas como a tendência inexorável à concentração do capital e dos mercados, apontada por Marx e Steindl. Porém, a consequência social dessas transformações para o pequeno empresário, de acordo com Mills, é uma radical mudança na sua inserção social: em analogia com o conceito de lumpem-proletariado, o pequeno empresário participaria da lumpem-burguesia, ocupando o nível mais baixo do mundo dos negócios. A partir dessa visão, entender o papel da pequena produção na contemporaneidade requereria, além de abordagens quantitativas, desvendar estratégias de sobrevivência de parte da população que não encontra inserção produtiva no mundo dos grandes negócios, sacudido por ondas tecnológicas e organizacionais poupadoras de postos de trabalho.

Uma outra abordagem para tentar entender a gênese da pequena produção é oferecida pela literatura que se ocupa dos conceitos de proprietários-gerentes de pequenos negócios e de empreendedorismo. Como reportado por Fillion (1999), a literatura nessa área vem crescendo exponencialmente nas últimas décadas, com um número cada vez maior de pesquisadores dedicados ao tema. No entanto, ainda não existem indícios de que mínimos princípios teóricos tenham sido aceitos, não havendo consenso nem mesmo quanto ao próprio conceito de empreendedor.

Desde o século XVIII, os economistas reconheciam o importante papel dos empreendedores no processo de desenvolvimento. É atribuída a Cantillon (1775, apud Schumpeter, 1949) a introdução do termo "entrepreneur" na literatura econômica. Inicialmente, os economistas associavam o empreendedor a pessoas que aproveitavam as oportunidades de mercado, visando obter lucros, assumindo os riscos inerentes à operação. Posteriormente, Say (apud Schumpeter, 1949), ao distinguir empreendedores de capitalistas, lançou as bases para o conceito que associa empreendedores à inovação, conceito esse que teve em Schumpeter seu grande difusor. O empresário inovador schumpeteriano, principal ator das mudanças econômicas no capitalismo avançado, é aquele capaz de reunir informações sobre o avanço tecnológico e as necessidades mercadológicas para aproveitar novas oportunidades, até então inexploradas.

Ainda no campo da economia, Baumol (1993) identificou dois tipos de empreendedores: os organizadores de negócios e os inovadores, tal como descrito por Schumpeter. Porém, a contribuição desses pensadores nessa área é limitada, uma vez que eles não estão preocupados em entender o comportamento dos empreendedores. Para Fillion (1993), os economistas interessados no tema estão à margem do mainstream da disciplina, sendo que os esforços mais recentes de Baumol, no sentido de entender a importância do surgimento de novos empresários, não foram continuados.

A tarefa de tentar entender as motivações por trás do comportamento empresarial foi assumida por um conjunto de pesquisadores denominados comportamentalistas. Para eles, as necessidades de realização individual e de poder seriam as 
principais variáveis explicativas do comportamento empreendedor. Essa concepção foi bastante criticada. Primeiro, por não conseguir relacionar, de forma convincente, as necessidades pessoais com o sucesso dos empreendedores. Segundo, por não levar em consideração que a necessidade de realização individual requer valores sociais que estimulem e valorizem a aceitação dos riscos inerentes à atividade do empreendedor. Em outras palavras, o comportamento empreendedor surge e cresce em determinadas estruturas sociais que criam instituições mais ou menos favoráveis a atividades empreendedoras.

\section{CONSIDERAÇÕES FINAIS}

A revisão feita neste trabalho conduz o leitor à percepção de que há uma menor probabilidade de sobrevivência dos pequenos negócios, comparativamente aos grandes, mas que, apesar disso, pequenas empresas podem permanecer viáveis mesmo quando a maioria delas não consegue alcançar uma escala mínima eficiente de produção.

Chegou o momento, então, de sintetizar as ideias dos autores examinados em torno das razões para a sobrevivência e dificuldades enfrentadas pelas pequenas empresas.

Dentre as razões para a sobrevivência salientam-se:

- ocupam espaços em segmentos produtivos dos quais as grandes empresas se apossam de maneira esporádica ou incompleta;

- atuam em uma relação de complementaridade e subordinação à grande empresa;

- por pagarem um salário menor, condição para se tornarem competitivas, e terem custos de produção mais elevados, tornam-se parâmetro para as grandes empresas, elevando, por transferência, o excedente destas últimas;

- uma oferta elástica de empresários e a inexistência de barreiras à entrada nos setores marcados por forte concorrência impedem que alguma empresa em particular possa se aproveitar das economias de escala de forma duradoura, abrindo espaço, portanto, para o surgimento de novas pequenas empresas;

- sempre existiriam pessoas dispostas a assumir riscos, reunindo mão de obra e capital na instalação de uma pequena empresa pela satisfação de serem chamados de homens de negócios, ainda que pudessem ganhar mais na função de gerente assalariado;

- o sistema de subcontratação de pequenas empresas pelas grandes torna funcional a existência das primeiras, na medida que tal sistema enseja a redução de custos das últimas;

- a impossibilidade de padronização dos produtos, o atendimento a pequenos mercados locais, a assimilação tardia de inovações tecnológicas e peculiari- 
dades de matéria-prima seriam características propicias para a atuação de pequenas empresas;

- atuam em segmentos ou espaços geográficos onde os incentivos para inovações poupadoras de trabalho são escassos e a mão de obra, barata e desorganizada. A necessidade de reduzir os preços das mercadorias é facilmente transformada em arrocho salarial;

- no oligopólio competitivo, as empresas líderes em preço convivem bem com as pequenas empresas que ocupam fatias pouco ponderáveis do mercado. $\mathrm{O}$ custo de eliminação das pequenas empresas não compensaria os ganhos em termos de expansão do poder de mercado. Haveria também desdobramentos políticos indesejáveis em decorrência dessa eliminação: explicitação de uma situação de monopólio e profundo descontentamento de um grande número de pessoas que vivem em torno da pequena empresa, algo que desembocaria na perda de votos para os governantes;

- possibilidade de convivência de novos métodos de produção ou de organização industrial, introduzidos pelas grandes empresas, com antigas formas localizadas nas pequenas unidades.

Quanto às dificuldades destacam-se:

- acesso ao crédito e a novas tecnologias;

- barreiras para a compra de equipamentos sofisticados e realização de gastos com propaganda, devido à baixa capitalização;

- incapacidade do pequeno empresário pensar a empresa em termos estratégicos, pois ele precisa "fazer de tudo";

- reduzido poder para barganhar reduções nos custos das compras e de transportes, por conta das diminutas escalas de produção;

- baixa taxa de lucro devido à intensa concorrência nos setores povoados por pequenas empresas;

- limitada flexibilidade financeira para institucionalizar departamentos de pesquisa e desenvolvimento ou estabelecer convênios com universidades com o objetivo de gerar inovações.

Diante da constatação empírica da importância da pequena empresa, não só no Brasil, como em vários outros países, atacar essas dificuldades através de políticas públicas é altamente relevante do ponto de vista econômico e social.

\section{REFERÊNCIAS BILIOGRÁFICAS}

BAUMOL, W. J. (1993), Formal entrepreneurship theory in economics: existence and bounds. Journal of Business Venturing, 7(3): 197-210.

BELLUZZO, L. G. M. (1987). Valor e capitalismo: um ensaio sobre economia política. São Paulo: Bienal. 
DAVIES, S., HALTIWANGER, J. \& S. SCHUH, S. (1996). Small business and job creation: dissecting the myth and reassessing the facts. Small Business Economics, 8 (4): 297-315.

FILLION, L. J. (1999). Empreendedorismo: empreendedores e proprietários-gerentes de pequenos negócios. Revista de Administração de Empresas, 34(2): 6-20.

JULIEN, P. A. (1993). Small business as a research subject: some reflections on knowledge of small business and its effects on economic theory. Small Business Economics, 5 (2): 157-166.

LEMOS C. (2003). Micro, Pequenas e Médias Empresas no Brasil: novos requerimentos de políticas para a promoção de Sistemas Produtivos Locais. Rio de Janeiro: UFRJ-IE/COPPE (Tese de Doutorado).

LOVEMAN, G. \& SENGENBERGER, W. (1991). The re-emergence of small-scale production: an international comparison. Small Business Economics, 3 (4): 1-37.

MARSHALL, A. ([1890] 1982). Princípios de Economia. São Paulo: Abril Cultural.

MARX, K. ([1867] 1982). O Capital. São Paulo: Abril Cultural.

MAZZUCCHELLI, F. (1985). A contradição em processo: O capitalismo e suas crises. São Paulo: Brasiliense.

MILLS, W. (1969). A nova classe média. Rio de Janeiro: Zahar Editores.

MONTAÑO, C. (1999). Microempresa na era da globalização. Porto Alegre: Cortez Editora.

NAPOLEONI, C. (1988). Smith, Ricardo e Marx. Rio de Janeiro: Graal.

PIORE M. \& SABEL, C. (1984). The second industrial divide: possibilities for prosperity. New York: Basic Books.

SATO, A. (1977). Pequenas e Médias Empresas no Pensamento Econômico. Campinas: Unicamp (Dissertação de Mestrado em Economia).

SCOTT, A. \& STORPER, M. (1987). High technology industry and regional development: a theoretical critique and reconstruction. International Social Science Review, 112: 215-232.

SEBRAE (2005). Boletim Estatístico de Micro e Pequenas Empresas. Brasília: Serviço Brasileiro de Apoio a Micro e Pequenas Empresas.

SCHUMPETER, J. A. ([1912] 1982). A Teoria do Desenvolvimento Econômico. São Paulo: Abril Cultural.

SCHUMPETER, J. A. ([1942] 1961). Capitalismo, Socialismo e Democracia. Rio de Janeiro: Fundo de Cultura.

SCHUMPETER, J. A. (1949). Economic theory and entrepreneurial history. Change and the entrepreneur. Reprinted in Schumpeter: essays on entrepreneurs, innovations, business cycles and capitalism (edited by Clemence, R.V.). New Brunswick: Transaction Publishers, 1989.

STEINDL, J. ([1945] 1990). Pequeno e Grande Capital: Problemas Econômicos do Tamanho das Empresas. São Paulo: HUCITEC/Unicamp.

STEINDL, J. ([1952] 1983). Maturidade e Estagnação no Capitalismo Americano. São Paulo: Abril Cultural.

TAGLIASSUCHI, M. (1987). Pequenas empresas: dependência econômica e participação política. Ensaios FEE. 8 (1): 65-69.

VOX POPULI (2007). Fatores Condicionantes e Taxa de Mortalidade das MPEs 2005. Belo Horizonte.

WINTER, S. (1995). Small and medium-size enterprises in economic development-possibilities for research and policy. Washington: The World Bank, Policy Research Working Paper. 